\title{
The Jump Size Distribution of the Commodity Spot Price and Its Effect on Futures and Option Prices
}

\author{
L. Gómez-Valle, Z. Habibilashkary, and J. Martínez-Rodríguez \\ Departamento de Economa Aplicada e IMUVA, Facultad de Ciencias Económicas y Empresariales, Universidad de Valladolid, \\ Avenida del Valle de Esgueva 6, 47011 Valladolid, Spain
}

Correspondence should be addressed to J. Martínez-Rodríguez; julia@eco.uva.es

Received 12 July 2017; Accepted 30 August 2017; Published 18 October 2017

Academic Editor: Lucas Jodar

Copyright (C) 2017 L. Gómez-Valle et al. This is an open access article distributed under the Creative Commons Attribution License, which permits unrestricted use, distribution, and reproduction in any medium, provided the original work is properly cited.

In this paper, we analyze the role of the jump size distribution in the US natural gas prices when valuing natural gas futures traded at New York Mercantile Exchange (NYMEX) and we observe that a jump-diffusion model always provides lower errors than a diffusion model. Moreover, we also show that although the Normal distribution offers lower errors for short maturities, the Exponential distribution is quite accurate for long maturities. We also price natural gas options and we see that, in general, the model with the Normal jump size distribution underprices these options with respect to the Exponential distribution. Finally, we obtain the futures risk premia in both cases and we observe that for long maturities the term structure of the risk premia is negative. Moreover, the Exponential distribution provides the highest premia in absolute value.

\section{Introduction}

In the literature, the commodity price usually follows a diffusion process with continuous paths when pricing commodity derivatives. Although this assumption is very attractive because of its computational, convenience, theoretical derivation and statistical properties, [1-4] others found significant evidence of the presence of jumps in commodity prices.

In traditional jump-diffusion commodity models, the functions of the stochastic processes and the market prices of risk are usually specified as simple parametric functions, for pure tractability and simplicity. Furthermore, the functions of the models are usually chosen to provide an affine model which has a known closed-form solution. For example, [5] considers a three-factor model where the spot price follows a jump-diffusion stochastic process. In [6] existing commodity valuation models were extended to allow for stochastic volatility and simultaneous jumps in the spot price and volatility. The standard geometric Brownian motion augmented by jumps was used by [7] to describe the underlying spot and the mean reverting diffusion processes for the interest rate and convenience yield in gold and copper price models. In [8] a seasonal mean reverting model with jumps and Heston-type stochastic volatility is analyzed.
We consider, in this paper, a two-factor jump-diffusion commodity model, where one of the factors is the commodity spot price and the other is the convenience yield. These factors are often used in the commodity literature. For example, $[9,10]$ propose affine models with these two factors, though they do not consider jumps. Then, all the functions can be easily estimated and the commodity derivatives priced. However, there is not any empirical evidence or consensus that affine models are the best models to price commodity futures. Furthermore, the market prices of risk are not observed in the markets. If we considered other more realistic functions for the state variables or the market prices of risk or even a nonparametric approach, then, the model would not be affine anymore, a closedform solution could not be obtained, and, therefore, the estimation of the market prices of risk would not be possible. However, [11] shows a new approach to estimate the whole functions of the model although a closed-form solution is not known. They even apply it to a jump-diffusion model where the jump follows a Normal distribution. Finally, they estimate the whole functions with a nonparametric technique in order to avoid imposing arbitrary functions on the model. 
Other authors have found seasonal patterns in commodity markets and this fact has been taken into account in their models; see [12-15].

In this paper, we price natural gas futures assuming that the spot price follows a diffusion process and, then, we also consider a jump-diffusion process with a Normal jump size distribution as in [11] but for a higher prediction period of time. Moreover, we also assume that the jump size follows an Exponential distribution in order to make some comparisons and analyze the role of the jump size distribution. We find that for short maturities the Normal distribution provides more accurate futures prices. However, the Exponential distribution shows the lowest error for long maturities. Furthermore, for long maturities, the models with both distributions underprice the futures in the market, but the futures prices with the Exponential distribution are higher than with the Normal distribution. Moreover, they are closer to the observed ones. Then, in order to complement [11], we also price futures options when the jump is not taken into account and when Normal as well as an Exponential jump size distributions are considered. In this case, we see that the differences between the prices are higher (in particular for out of money options).

Futures prices are potentially a valuable source of information on market expectations of asset prices. In fact, financial investors use futures contracts to hedge against commodity price risk. However, exploiting this information is difficult in practice, because of the presence of a risk premium between the current futures price and the expected spot price of the underlying asset. Moreover, understanding this premium is very important; see [16]. Therefore, in this paper, we also show an out-of-sample analysis of the natural gas futures risk premia. We find that the risk premium with the Exponential distribution is negative more times than with the Normal distribution. In all the cases, we use natural gas data traded at NYMEX and a nonparametric approach to estimate the whole functions of the two-factor model.

The rest of the paper is organized as follows. Section 2 shows a two-factor jump-diffusion model to price commodity derivatives. Section 3 prices futures with a diffusion model and a jump-diffusion model, when the jump size follows a Normal as well as an Exponential distribution. Then a comparison is made. Section 4 compares futures option prices when the jump follows a Normal or an Exponential distribution. Section 5 analyzes the futures risk premium and, finally, Section 6 concludes. All the implementation has been done using MATLAB software.

\section{The Valuation Model}

In this section, we introduce a commodity model with two state variables: the spot price and the convenience yield, for pricing commodity derivatives; see also [11, 17]. We assume that the spot price follows a jump-diffusion process, because commodity prices usually suffer from abrupt changes in the markets; see [1]. However, we assume that the convenience yield is a diffusion process because its behaviour is not affected by extreme changes; see, for example, [6].
Define $\left(\Omega, \mathscr{F},\left\{\mathscr{F}_{t}\right\}_{t \geq 0}, \mathscr{P}\right)$ as a complete filtered probability space which satisfies the usual conditions where $\left\{\mathscr{F}_{t}\right\}_{t \geq 0}$ is a filtration; see [18-20]. Let $S$ be the spot price and $\delta$ the instantaneous convenience yield. We assume that these factors follow this joint jump-diffusion stochastic process:

$$
\begin{aligned}
d S(t)= & \mu_{S}(S(t), \delta(t)) d t+\sigma_{S}(S(t), \delta(t)) d W_{S}(t) \\
& +d J(t), \\
d \delta(t)= & \mu_{\delta}(S(t), \delta(t)) d t+\sigma_{\delta}(S(t), \delta(t)) d W_{\delta}(t),
\end{aligned}
$$

where $\mu_{S}$ and $\mu_{\delta}$ are the drifts and $\sigma_{S}$ and $\sigma_{\delta}$ the volatilities. Moreover, $W_{S}$ and $W_{\delta}$ are Wiener processes and the impact of the jump is given by the compound Poisson process, $J(t)=\sum_{i=1}^{N(t)} Y_{i}$, with jump times $\left(\tau_{i}\right)_{i \geq 1}$, where $N(t)$ represents a Poisson process with intensity $\lambda(S, \delta)$ and $Y_{1}, Y_{2}, \ldots$ is a sequence of identically distributed random variables with a probability distribution $\Pi$. We assume that $W_{S}$ and $W_{\delta}$ are independent of $N$, but the standard Brownian motions are correlated with

$$
\left[W_{S}, W_{\delta}\right](t)=\rho t
$$

We also suppose that the jump magnitudes and the jump arrivals time are uncorrelated with the diffusion parts of the processes. We assume that the functions $\mu_{S}, \mu_{\delta}, \sigma_{S}, \sigma_{\delta}, \lambda$ and $\Pi$ satisfy suitable regularity conditions: see $[20,21]$. Under the above assumptions, a commodity futures price at time $t$ with maturity at time $T, t \leq T$, can be expressed as $F(t, S, \delta ; T)$ and at maturity it verifies that $F(T, S, \delta ; T)=S$.

We assume that the market is arbitrage-free. Then, there exists an equivalent martingale measure, Q-measure, which is known as the risk-neutral measure; see extended Girsanovtype measure transformation in [22]. The state variables of the model (1) under the risk-neutral measure are as follows:

$$
\begin{aligned}
d S= & \left(\mu_{S}-\sigma_{S} \theta^{W_{S}}+\lambda^{\mathscr{Q}} E_{Y}^{\mathscr{Q}}\left[Y_{1}\right]\right) d t+\sigma_{S} d W_{S}^{\mathscr{Q}} \\
& +d \widetilde{J}^{\mathscr{Q}}(t) \\
d \delta= & \left(\mu_{\delta}-\sigma_{\delta} \theta^{W_{\delta}}\right) d t+\sigma_{\delta} d W_{\delta}^{\mathscr{Q}},
\end{aligned}
$$

where $W_{S}^{\mathbb{Q}}$ and $W_{\delta}^{Q}$ are the Wiener processes under the risk-neutral measure and $\left[W_{S}^{\mathbb{Q}}, W_{\delta}^{\mathbb{Q}}\right](t)=\rho t$. The market prices of risk associated with $W_{S}$ and $W_{\delta}$ Wiener processes are $\theta^{W_{S}}(S, \delta)$ and $\theta^{W_{\delta}}(S, \delta)$, respectively. Finally, $\widetilde{J}^{Q}(t)=$ $\sum_{i=1}^{N^{\mathscr{Q}}(t)} Y_{i}-\lambda^{\mathscr{Q}} t E_{Y}^{\mathscr{Q}}\left[Y_{1}\right]$ is the compensated compound Poisson process under $Q$-measure, the intensity of the Poisson process $N^{\mathscr{Q}}(t)$ is $\lambda^{\mathscr{Q}}(S, \delta)$, and $E^{\mathscr{Q}}$ denotes the expectation under the $Q$-measure. Then, the futures price can be expressed as

$$
F(t, S, \delta ; T)=E^{\mathscr{Q}}[S(T) \mid S(t)=S, \delta(t)=\delta] .
$$

Let $V\left(t, S, \delta, T_{2} ; T_{1}\right)$ be the price of a European call option that matures on $T_{1}$ on a futures contract that expires at $T_{2}$, $T_{1} \leq T_{2}$, and $K$ is the strike price. Then, analogously to (4), an 
European commodity futures option is priced as the expected discounted payoff under the $Q$-measure; see $[6,22]$ :

$$
\begin{aligned}
& V\left(t, S, \delta, T_{2} ; T_{1}\right)=E^{\mathscr{Q}}\left[e^{-\int_{t}^{T_{1}} r(u) d u}\right. \\
& \quad \cdot \max \left(F\left(T_{1}, S\left(T_{1}\right), \delta\left(T_{1}\right) ; T_{2}\right)-K, 0\right) \mid S(t) \\
& \quad=S, \delta(t)=\delta]
\end{aligned}
$$

where $r$ denotes the instantaneous risk-free interest rate, which is assumed to be constant. Moreover, $\tau_{1}=T_{1}-t$ and $\tau_{2}=T_{2}-T_{1}$ are the maturity of the option contract and futures contract, respectively.

\section{Valuation of Commodity Futures with NYMEX Data}

In this section, by means of an empirical application with natural gas NYMEX data, we illustrate the advantages and disadvantages of modelling the spot price with a jumpdiffusion process with an Exponential distribution and a Normal distribution. In all the cases, we use the approach, the nonparametric techniques and the in-sample data (January 2004-December 2014) as in [11], to estimate the risk-neutral functions. However, we increase the out-of-sample period where we price the natural gas derivatives from January till July 2015.

In this empirical application, we use the model stated in Section 2, where the factors are the commodity spot price and the convenience yield. For simplicity and tractability and as usual in the literature, we also assume that the distribution of the jump size under $Q$-measure is known and equal to the distribution under $\mathscr{P}$-measure. This means that all risk premium related to the jump is artificially absorbed by the change in the intensity of the jump from $\lambda$ under the physical measure to $\lambda^{\mathscr{Q}}$ under the risk-neutral measure; see $[8,11$, 23]. Moreover, we assume the jump size follows a Normal distribution $N\left(0, \sigma_{Y}\right)$ (see [11]) or an Exponential distribution $\operatorname{Exp}\left(\sigma_{Y}\right)($ see $[6,24,25])$ among others.

In order to price natural gas futures, we use daily natural gas data from the NYMEX in Quandl platform. Natural gas spot prices were obtained from the U.S. Energy Information Administration (EIA). The sample period covers from January 2004 to July 2015. More precisely, we use data from January 2004 to December 2014 to estimate the risk-neutral functions as in [11] and, then, we keep data from January to July 2015 to make our out-of-sample analysis of the futures prices.

As it is well known in the literature, the convenience yield is not observed in the markets. Then, following [9], we approximate it by the following result

$$
\delta_{T-1, T}=r_{T-1, T}-12 \ln \left[\frac{F(t, S, \delta ; T)}{F(t, S, \delta ; T-1)}\right],
$$

where $r_{T-1, T}$ denotes the forward interest rate between $T-1$ and $T$. We obtain this forward interest rate with two daily $T$ Bill rates with maturities as close as possible to the futures contracts' ones in order to compute $\delta_{1,2}$, the one-month ahead annualized convenience yield. The latter is identified with the instantaneous convenience yield $\delta_{0,1}$; see $[9,11]$ for more details.

In order to estimate the risk-neutral functions of the jump-diffusion models, we follow the same approach as [11]. Note that similar techniques have been proposed for interest rate derivatives; see $[26,27]$.

Firstly, we obtain the compensated risk-neutral drift of the spot price by means of the following equality which relates the futures slope in the origin with the drift of the spot in the stochastic process under Q-measure; see [11] for more detail:

$$
\frac{\partial F}{\partial T}(t, S, \delta ; t)=\left(\mu_{S}-\sigma_{S} \theta^{W_{S}}+\lambda^{\mathscr{Q}} E_{Y}\left[Y_{1}\right]\right)(t)
$$

We approximate the partial derivative by means of numerical differentiation

$$
\left.\frac{\partial g}{\partial T}\right|_{T=t}=\frac{-25 g(t)+48 g(t+\Delta)-36 g(t+2 \Delta)+16 g(t+3 \Delta)-3 g(t+4 \Delta)}{12 \Delta}+O\left(\Delta^{4}\right)
$$

with futures prices with maturities equal to $1,2,3$, and 4 months. Then, we estimate it by means of the NadarayaWatson estimator; see [28] for more details on this estimation technique.

Secondly, for the risk-neutral jump intensity, we use a result proposed in [11] which relates the futures slope in the origin with the spot price, spot price volatility, and parameters of jump size distribution under Q-measure:

$$
\frac{\partial(S F)}{\partial T}(t, S, \delta ; t)=\left(2 S \frac{\partial F}{\partial T}+\sigma_{S}^{2}+\lambda^{Q} E_{Y}\left[Y_{1}^{2}\right]\right)(t)
$$

Initially, [11] assumed that the jump size followed a Normal distribution as $Y_{1} \leadsto N\left(0, \sigma_{Y}^{2}\right)$, then, $E_{Y}\left[Y_{1}\right]=0$, and $\sigma_{Y}^{2}=E_{Y}\left[Y_{1}^{2}\right]$. Furthermore, it is well known that

$$
\begin{aligned}
E_{Y}\left[Y_{1}^{2 k}\right] & =\sigma_{Y}^{2 k} \prod_{n=1}^{k}(2 k-1), \\
E_{Y}\left[Y_{1}^{2 k-1}\right] & =0, \quad k=1,2,3, \ldots
\end{aligned}
$$

In this paper we also assume that the jump size follows an Exponential distribution as $Y_{1} \leadsto \operatorname{Exp}\left(\sigma_{Y}\right)$; then:

$$
E_{Y}\left[Y_{1}^{k}\right]=k ! \sigma_{Y}^{k}, \quad k=1,2,3, \ldots
$$


This jump size distribution has also been considered by [29] for the volatility and [30] for interest rates. This assumption could be useful for pricing during periods in which positive jumps are expected to dominate negative jumps, for example, coming out of an economic crisis (see [30]) or in certain economic regimes (see [31]).

With both distributions, the parameters of the jump size distribution and the spot price volatility, $\sigma_{S}$, are estimated by means of a system of moment equations of a jump-diffusion process (see $[11,32,33])$ :

$$
\begin{aligned}
& M_{S}^{2}(S, \delta) \\
& =\lim _{\Delta t \rightarrow 0} \frac{1}{\Delta t} E\left[(S(t+\Delta t)-S(t))^{2} \mid S(t)=S, \delta(t)=\delta\right] \\
& =\sigma_{S}^{2}(S, \delta)+\lambda(S, \delta) E_{Y}\left[Y_{1}^{2}\right], \\
& M_{S}^{k}(S, \delta) \\
& =\lim _{\Delta t \rightarrow 0} \frac{1}{\Delta t} E\left[(S(t+\Delta t)-S(t))^{k} \mid S(t)=S, \delta(t)=\delta\right] \\
& =\lambda(S, \delta) E_{Y}\left[Y_{1}^{k}\right], \quad k \geq 3 .
\end{aligned}
$$

More precisely, we use moments $M_{S}^{2}, M_{S}^{4}$, and $M_{S}^{6}$ for the Normal distribution and moments $M_{S}^{2}, M_{S}^{3}$, and $M_{S}^{4}$ for the Exponential distribution; see, for example, [34, 35], respectively. Then, Nadaraya-Watson estimator is applied. Once we estimate the parameters of the jump size distribution and the spot volatility and approximate the previous partial derivatives $\left.(\partial F / \partial T)\right|_{T=t}$ and $\left.(\partial(S F) / \partial T)\right|_{T=t}$, we replace them in (9). Then, we estimate the risk-neutral jump intensity of the spot price with the Nadaraya-Watson estimator.

As the convenience yield follows a diffusion process, we estimate its risk-neutral drift by means of

$$
\begin{aligned}
& \frac{\partial(\delta F)}{\partial T}(t, S, \delta ; t) \\
& \quad=\left(\delta \frac{\partial F}{\partial T}+S\left(\mu_{\delta}-\sigma_{\delta} \theta^{W_{\delta}}\right)+\rho \sigma_{S} \sigma_{\delta}\right)(t)
\end{aligned}
$$

see [11]. In order to estimate the correlation, we use the moment

$$
\begin{aligned}
M_{S, \delta}^{1}(S, \delta) & =\lim _{\Delta t \rightarrow 0} \frac{1}{\Delta t} \\
\cdot & E[(S(t+\Delta t)-S(t))(\delta(t+\Delta t)-\delta(t)) \mid S(t) \\
& =S, \delta(t)=\delta]=\rho(S, \delta) \sigma_{S}(S, \delta) \sigma_{\delta}(S, \delta),
\end{aligned}
$$

and the Nadaraya-Watson estimator; see [36] for more details. Later, we replace the estimated covariance and the approximations of $\left.(\partial F / \partial T)\right|_{T=t}$ and $\left.(\partial(\delta F) / \partial T)\right|_{T=t}$ in (13) and we estimate the risk-neutral drift of the convenience yield by means of the Nadaraya-Watson estimator.

Finally, the volatility of the convenience yield under $\mathscr{P}$ measure is equal to the volatility under $Q$-measure. Hence, we estimate $\sigma_{\delta}$ by means of the second order moment of a diffusion process:

$$
\begin{aligned}
M_{\delta}^{2} & (S, \delta)=\lim _{\Delta t \rightarrow 0} \frac{1}{\Delta t} \\
\cdot & E\left[(\delta(t+\Delta t)-\delta(t))^{2} \mid S(t)=S, \delta(t)=\delta\right] \\
& =\sigma_{\delta}^{2}(S, \delta),
\end{aligned}
$$

and Nadaraya-Watson estimator, with spot and convenience yield data.

Up to this point, we have focused on the estimation of the risk-neutral functions of jump-diffusion processes. If we assume that the spot price follows a diffusion stochastic process, the factors of the model will follow this joint diffusion stochastic process under Q-measure:

$$
\begin{aligned}
& d S=\left(\mu_{S}-\sigma_{S} \theta^{W_{S}}\right) d t+\sigma_{S} d W_{S}^{Q}, \\
& d \delta=\left(\mu_{\delta}-\sigma_{\delta} \theta^{W_{\delta}}\right) d t+\sigma_{\delta} d W_{\delta}^{Q},
\end{aligned}
$$

with $\left[W_{S}^{Q}, W_{\delta}^{\mathbb{Q}}\right](t)=\rho t$.

The estimation of these functions is made by means of the approach in [37] and the Nadaraya-Watson estimator, with the same natural gas data and numerical differentiation approximation as the jump-diffusion model.

For analyzing the effect of the jumps on the natural gas futures prices, we price natural gas futures with a diffusion model (DM) as well as a jump-diffusion model with a Normal jump size distribution (JDMN) and an Exponential distribution (JMDExp). In order to price natural gas futures it is necessary to solve a partial integrodifferential equation or, equivalently, by means of Feynman-Kac Theorem the expectation in (4). As we use nonparametric methods a closed-form solution cannot be found. Recently, several numerical methods have been developed to solve this kind of problems; see $[38,39]$.

In this paper, we use the Monte Carlo simulation approach because it is widely used by practitioners in the markets, especially for multiple factor models because of its simplicity and efficiency, [40]. More precisely, we consider 5000 simulations and a daily time step, $\Delta t=1 / 250$. We price natural gas futures with maturities from 1 to 44 months and we compare them with those traded at NYMEX along the outof-sample (January-July 2015). As measures of error, we use the root mean square error (RMSE) and the percentage root mean square error (PRMSE) for the out-of-sample:

$$
\begin{aligned}
\text { RMSE } & =\sqrt{\frac{1}{n} \sum_{t=1}^{n}\left(F_{t}-\widehat{F}_{t}\right)^{2}}, \\
\text { PRMSE } & =\sqrt{\frac{1}{n} \sum_{t=1}^{n}\left(\frac{F_{t}-\widehat{F}_{t}}{F_{t}}\right)^{2}},
\end{aligned}
$$

where $n$ is the number of observations, $F_{t}$ is the futures price traded at NYMEX, and $\widehat{F}_{t}$ is the predicted futures price with the different models. 
TABLE 1: RMSE and PRMSE for the out-of-sample (January-July 2015) for DM, JDMN, and JDMExp models.

\begin{tabular}{|c|c|c|c|c|c|c|}
\hline & & RMSE & & & PRMSE & \\
\hline & $\mathrm{DM}$ & JDMN & JDMExp & $\mathrm{DM}$ & JDMN & JDMExp \\
\hline $\mathrm{F} 1$ & 0.1582 & 0.1362 & 0.1398 & 5.7376 & 4.9326 & 5.0514 \\
\hline F6 & 0.1636 & 0.1744 & 0.1893 & 5.4787 & 5.9201 & 6.4430 \\
\hline F9 & 0.1472 & 0.1162 & 0.1531 & 4.5256 & 3.6732 & 4.9852 \\
\hline $\mathrm{F} 12$ & 0.2113 & 0.1529 & 0.1590 & 6.2670 & 4.6156 & 5.1349 \\
\hline F18 & 0.2651 & 0.2012 & 0.1466 & 7.7642 & 5.8706 & 4.5386 \\
\hline F24 & 0.3757 & 0.3172 & 0.2176 & 10.3069 & 8.6277 & 6.0603 \\
\hline $\mathrm{F} 30$ & 0.3826 & 0.3141 & 0.1630 & 10.7959 & 8.8260 & 4.5345 \\
\hline F36 & 0.4753 & 0.4199 & 0.3126 & 12.4319 & 10.8809 & 8.0727 \\
\hline F42 & 0.4295 & 0.3661 & 0.2254 & 11.8569 & 10.0716 & 6.1337 \\
\hline F44 & 0.5065 & 0.4413 & 0.2953 & 13.7741 & 11.9909 & 7.9929 \\
\hline
\end{tabular}

Table 1 shows a summary of the RMSE and PRMSE of the different models for the out-of-sample and for several maturities. $\mathrm{F} 1$ is the futures price with a maturity of 1 month, F6 with six months, and so on. In this table, we show that for short maturities the RMSE are usually lower than for long maturities. Besides, for very short maturities sometimes the diffusion model prices natural gas futures quite accurately, as for F6. However, for F1 and for maturities higher or equal to 9 months, jump-diffusion models provide lower errors than the diffusion model as in [11]. Moreover, for maturities lower than 18 months the JDMN is more accurate than the JDMExp, but for long maturities (higher or equal to 18 months) the results change and the JDMExp displays lower errors than the JDMN. Therefore, depending on the maturity of the futures to price, some models are more accurate than others. As far as the PRMSE is concerned, we reach the same conclusion but, for maturities longer or equal than 36 , the differences between the relative error of the JDMN and JDMExp are higher.

We now turn our attention to the absolute errors along the out-of-sample for some maturities. Figure 1 plots the absolute errors of the considered models for some maturities such as 6,18 , and 44 months. We show only these maturities because the behaviour of the rest is analogous. For example, for a maturity of 6 months, we observe that the errors of the DM are the lowest along the first months of the out-of-sample, although it changes for the last months. For longer maturities, for example 18 months, the JDExp model provides the lowest errors for a great number of months, followed by the JDN. Finally, when we consider the longest available maturity, the JDExp model is clearly the most accurate.

If we analyze the price behaviour along the out-of-sample, we observe high changes for short maturities, but they decrease when we increase the maturity. That is, the longer the maturity, the lower the price variations along the time. In order to illustrate this result, in Figure 2, we plot the futures prices traded at NYMEX and those priced with the different models considered in this paper (DM, JDMN, and JDMExp). As we can see in this figure, the highest variations are for F6 and the lowest are for F44. Focusing on the estimated prices, we observe that, in general, the DM provides the lowest prices and the JDMExp the highest prices for each maturity along the time for some maturities. We observe that the NYMEX
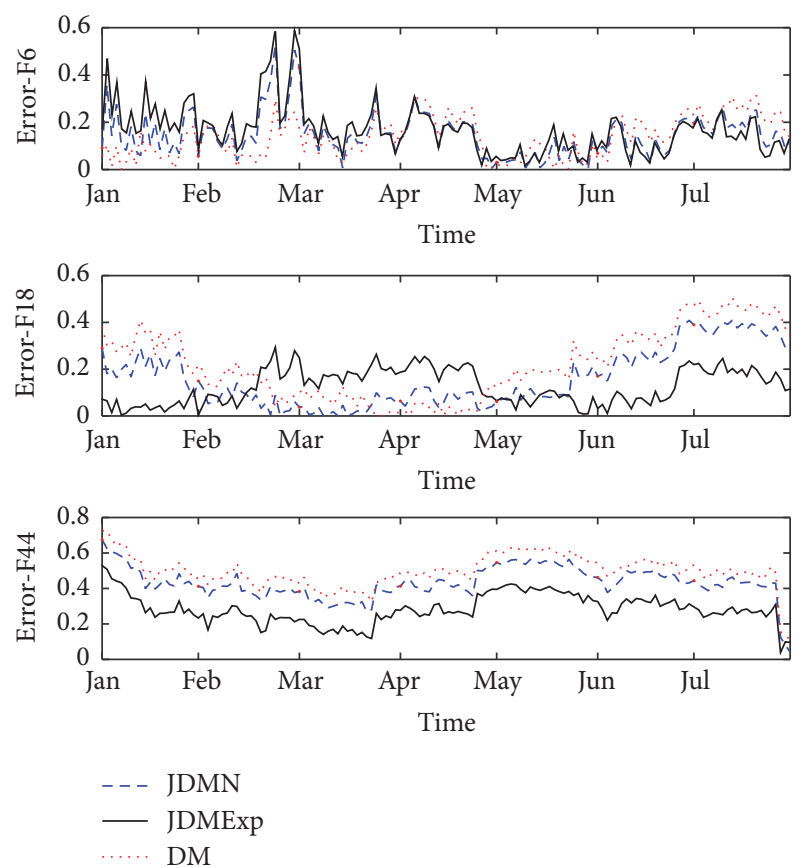

FIGURE 1: Absolute error of the futures prices for the out-of-sample (January-July 2015) with maturities: 6, 18, and 44 months. The absolute error for the DM is the red dotted line, the JDMN is the blue dash line, and the JDMExp is the black solid line.

and estimated futures prices usually rise when the maturity increases, but the rate of rising of the market prices is higher than the rate of the estimated prices with the different models. We also see that the estimated models overprice the NYMEX F6 futures in several months. However, in most of the cases, the JDMN and the DM underprice the NYMEX futures for a maturity of 18 months. Finally, for a maturity of 44 months, the whole estimated models underprice the NYMEX futures. Then, the higher the maturity the higher the possibility for natural gas futures to be underpriced by the different models, especially by the DM.

In conclusion, as in [11], the jump-diffusion models provide lower errors than the diffusion model apart from some 
TABLE 2: Ratios between the JDMN and JDMExp option prices.

\begin{tabular}{|c|c|c|c|c|c|c|c|c|c|c|c|c|}
\hline \multirow{2}{*}{$\begin{array}{l}\text { Strike } \\
\tau_{1} \backslash \tau_{2}\end{array}$} & \multicolumn{4}{|c|}{$95 \%$} & \multicolumn{4}{|c|}{$100 \%$} & \multicolumn{4}{|c|}{$105 \%$} \\
\hline & $3 \mathrm{~m}$ & $6 \mathrm{~m}$ & $9 \mathrm{~m}$ & $12 \mathrm{~m}$ & $3 \mathrm{~m}$ & $6 \mathrm{~m}$ & $9 \mathrm{~m}$ & $12 \mathrm{~m}$ & $3 \mathrm{~m}$ & $6 \mathrm{~m}$ & $9 \mathrm{~m}$ & $12 \mathrm{~m}$ \\
\hline $3 \mathrm{~m}$ & 0.91 & 0.76 & 0.65 & 0.59 & 0.91 & 0.70 & 0.52 & 0.42 & 0.94 & 0.63 & 0.36 & 0.19 \\
\hline $6 \mathrm{~m}$ & 0.88 & 0.73 & 0.63 & 0.58 & 0.88 & 0.68 & 0.52 & 0.43 & 0.90 & 0.62 & 0.40 & 0.24 \\
\hline $9 \mathrm{~m}$ & 0.80 & 0.68 & 0.60 & 0.58 & 0.79 & 0.63 & 0.50 & 0.43 & 0.79 & 0.56 & 0.37 & 0.26 \\
\hline $12 \mathrm{~m}$ & 0.80 & 0.69 & 0.62 & 0.60 & 0.78 & 0.63 & 0.51 & 0.46 & 0.78 & 0.57 & 0.40 & 0.29 \\
\hline
\end{tabular}

short maturities. Hence, this fact supports the use of jump processes when modelling the commodity price dynamics for pricing natural gas futures. As far as the jump size distribution is concerned, the JDMN prices are, in general, lower than the JDMExp prices. This is consistent with the assumptions made for the jump size distribution in Section 3. Under the Normal distribution the average jump size is zero, whereas under the Exponential distribution the average jump size is positive. Therefore, average impact of the jumps on the spot prices under the Normal distribution should be lower than under the Exponential distribution. Moreover, the Normal distribution provides the lowest error for maturities shorter than or equal 12 months, but the Exponential distribution is more accurate for longer maturities. This fact could be due to the very low natural gas spot price during the prediction period of time. Furthermore, investors in the market should take care of the possible overpricing or underpricing of these models depending on the maturity of the futures.

\section{Valuation of Futures Options}

In the previous section we have already seen the superiority of the jump-diffusion models over the diffusion models for pricing natural gas futures and that, for long maturities, the model with an Exponential distribution is more accurate than the other models. Hence, in this section we present the effect of the different jump size distributions on a different natural gas derivative: a futures option. In order to price this European call option we use the same NYMEX data and estimation methodology than in the previous section, but, now, the Monte Carlo method approximates (5) with 5000 simulations and a daily time step $(\Delta t=1 / 250)$.

We assume different option maturities, $\tau_{1}$, such as 3,6 , 9 , and 12 months, and different futures maturities, $\tau_{2}$, equal to $3,6,9$, and 12 months. We also assume that the strike price, which is a percentage of the natural gas spot price at the moment of its pricing, is equal to $95 \%, 100 \%$, and $105 \%$. Therefore, the options are priced in the money, at the money, and out of the money, respectively.

As the instantaneous interest rate is not observable, we use the three-month Treasury Bill rates of the US Federal Reserve at the valuation moment as a proxy. In the term structure literature, this Treasury Bill rate is also usually considered as a proxy of the instantaneous interest rate; see, for example, [33].

In this paper, we price the futures options the first day of the out-of-sample data, that is, on January 3, 2015, and we observe that the higher the strike price, the lower the option
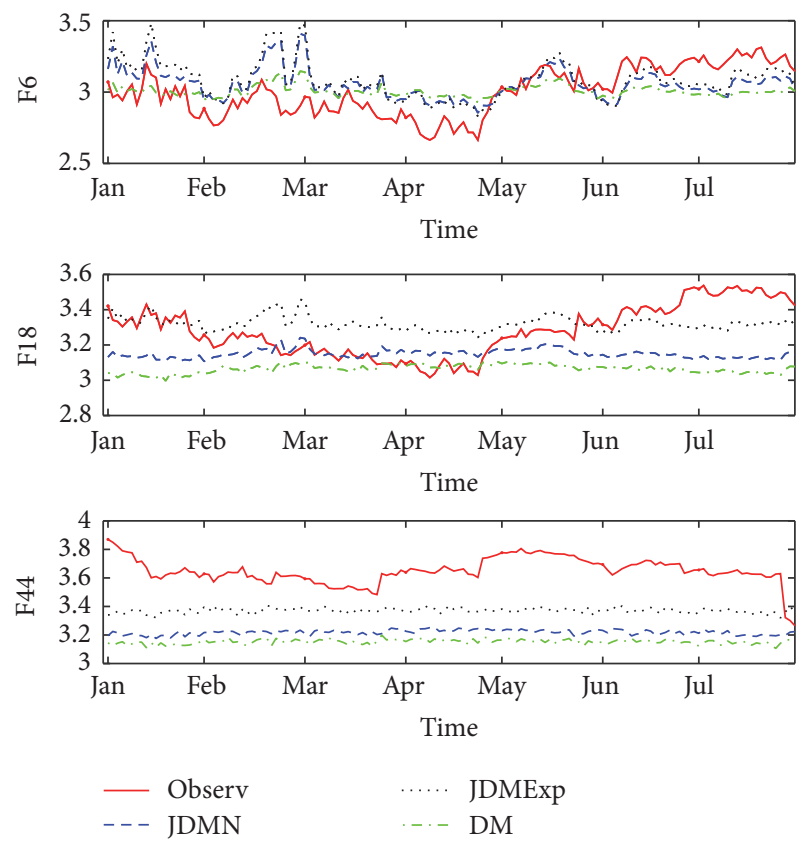

Figure 2: Natural gas futures prices (January-July 2015) with maturities: 6,18 , and 44 months. The NYMEX futures prices are the red solid line, the DM is the green dashed dotted line, the JDMN is the blue dash line, and the JDMExp is the black dotted line.

price. However, conclusions do not change if we consider other different days of the out-of-sample for valuation.

As we do not have observations of European natural gas option prices for different maturities, we compare the prices when the Normal and Exponential jump sizes are considered. In Table 2, we show some ratios between the JDMN and JDMExp for different strike prices and maturities on January 3, 2015. As we can see, for options and underlying futures with short maturities ( 3 months) the ratios are higher than $90 \%$. The main reason is that the futures prices with short maturities are quite similar for both distributions, although the futures prices with the Normal distribution are slightly lower. However, as we increase the maturities, especially of the futures, the ratios decrease considerably till $19 \%$. This fact is consistent with the high differences between the futures prices with both distributions when the maturity increases. Moreover, these differences are even higher because the futures price is the underlying of the option. Therefore, we conjecture that, in order to price futures options accurately, other stochastic variables should be considered in the model, such as the volatility or interest rates. 
This result can be very interesting for practitioners, because they should take into account the fact that the Exponential jump size distribution overprices option prices with respect to the Normal distribution, which is consistent with the results obtained in the previous section for jumpdiffusion futures prices. Finally, we see that the higher the strike price the lower the ratio. Therefore, the highest price differences can be found for the out of the money options.

\section{Futures Risk Premium}

The futures risk premium provides a link between natural gas futures and expected spot prices and it is a key measure in risk management. In particular, the term structure of commodity risk premia supplies additional information about the role of the net hedging pressure. Then, it is an important factor in understanding the markets and it deserves great attention.

In the literature, the risk premium is defined as the difference between the expected future spot price and the futures price; see $[25,41]$ among others:

$$
R P=E[S(T) \mid S(t)=S, \delta(t)=\delta]-F(t, S, \delta ; T) .
$$

Therefore, the risk premium is the reward for holding a risk rather than a risk-free investment; see [41]. In energy markets, the sign of the risk premium usually changes along the time, with the maturity of the futures and even with the market and the commodity; see for example [42].

On the one hand, commodity consumers may enter into a long position in futures contracts, because they want to insure against future increases in the spot price, so they accept prices over the expected spot price. On the other hand, commodity producers may enter into a short position in futures contracts because they wish to hedge their revenue risk. Since this decision is taken in advance, they accept prices below the expected spot price. Then, if the activity of consumers is greater than that of producers, there will be an excess of commercial participants looking to enter a long position. In this case, the net hedging pressure theory establishes that the futures price will be higher than the expected future spot price to induce speculators to balance the market by taking a short position. In contrast, if the hedging activity of producers is greater than that of consumers, there will be an excess of commercial participants looking to enter a short position. Then, the expected future spot price will be higher than the futures price to induce speculators to balance the market by taking a long position. Therefore, the commodity futures risk premia (in absolute value) can be seen as the return that speculators expect to receive to compensate the market; see [42].

In this section, we obtain the natural gas futures risk premia for the out-of-sample (January-July 2015). We use the natural gas futures prices traded at NYMEX for maturities between 1 and 24 months, but we also need to calculate $E[S(T) \mid S(t)=S, \delta(t)=\delta]$. In this case, the functions of the stochastic processes (1) are estimated directly from the moment conditions for the different jump distributions; see, for example, [34] for the Normal distribution and [35] for the Exponential distribution. The market prices of risk are not taken into account because there is not a change from the

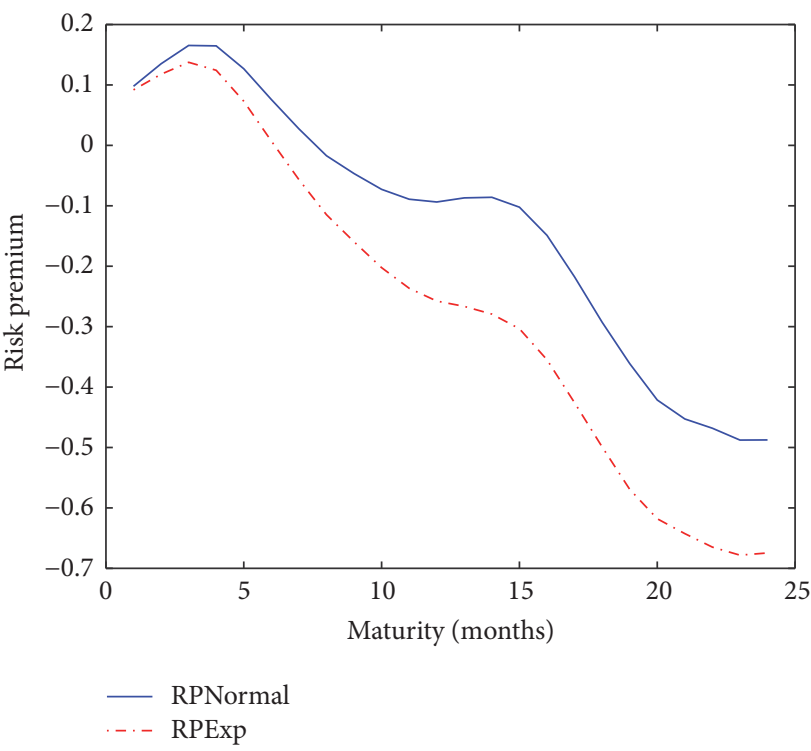

FIGURE 3: The risk premium as a function of time to maturity for the JDMN and JDMExp models.

physical to the risk-neutral measure. Then, these estimated functions are used to obtain $E[S(T) \mid S(t)=S, \delta(t)=\delta]$ by means of Monte Carlo simulation approach, with 5000 simulations and a daily time step $(\Delta t=1 / 250)$.

Figure 3 shows the term structure of natural gas risk premia with the Normal and the Exponential jump size distributions, hereafter RPNormal and RPExp, respectively. We calculate these values like the mean of the risk premia, for each maturity, in the out-of-sample. In this figure, both RPNormal and RPExp have, in general, the same behaviour although the risk premium under the Normal jump size distribution is always higher than the risk premium under the Exponential distribution. This fact is consistent with the mean of the distributions considered in each case. Furthermore, as it can be seen in Figure 3, the risk premium is positive for short maturities (approximately, up to 7 or 8 months for the Exponential and the Normal distribution, resp.). Following the net hedging pressure theory, for these short maturities the activity of the producers is higher than the consumers activity and the risk premium is the average return that speculators would receive by entering a long position in the natural gas futures markets and holding the futures to expiration. This means that the futures prices are below the expected spot prices and the futures curve is said to be normally backwardated; see [43]. However, for maturities higher than 7 or 8 months the risk premium starts to be negative. In this case, the futures prices are above the expected spot prices and, then, the curve is said to be in Normal contango; see [43]. Following the net hedging pressure theory, consumers have to offer an incentive to induce speculators to enter a short position, and the absolute value of the risk premia is the return that speculators expect to receive for balancing the market. More precisely, in general, the higher the maturity the more negative the risk premium and, then, speculators expect to receive a higher compensation to balance the market. 

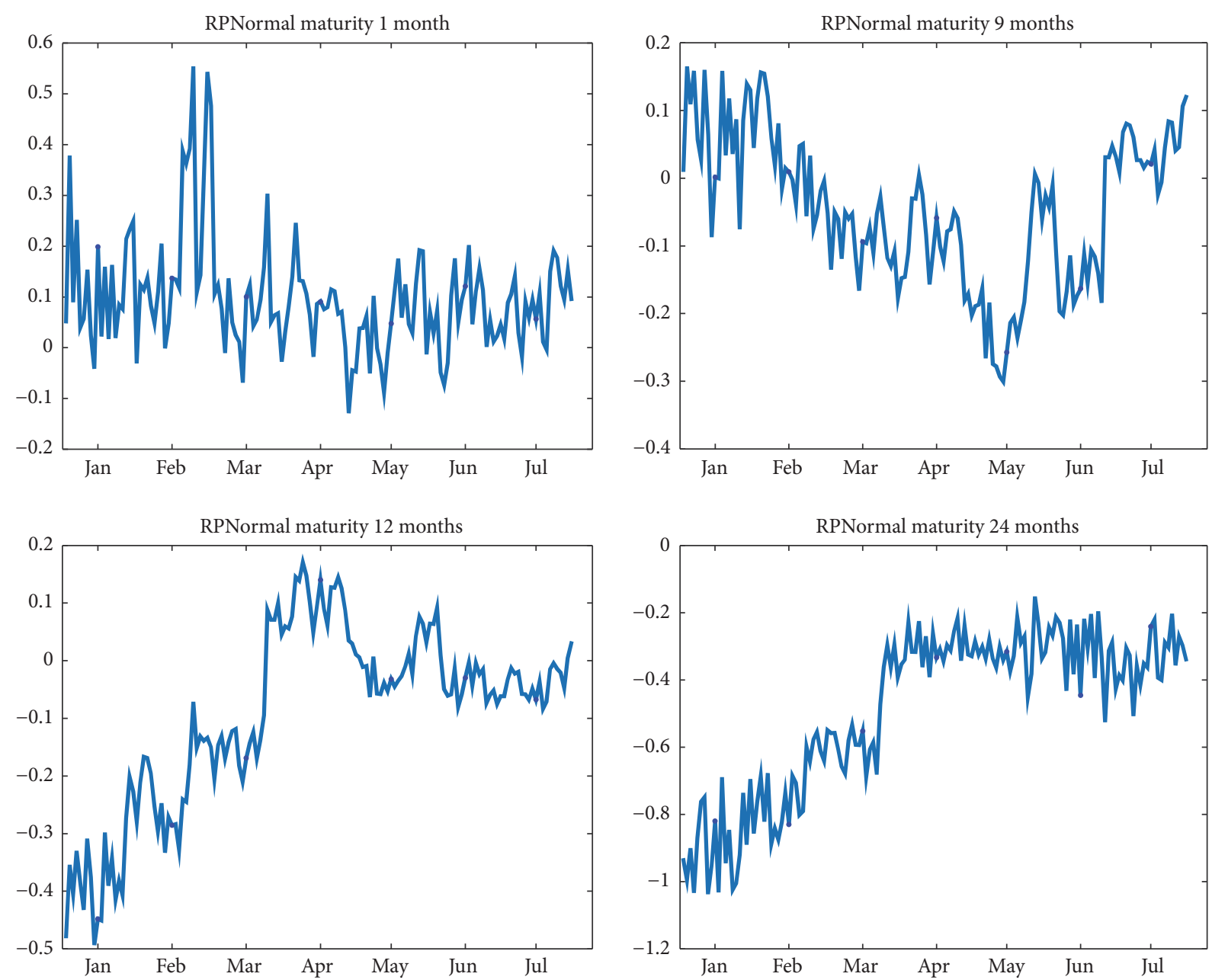

FIGURE 4: The risk premium for the JDMN model along the out-of-sample, for maturities 1, 9, 12, and 24 months.

In Figures 4 and 5, we plot the estimated risk premium as a function of time when the jump size follows a Normal and an Exponential distribution, respectively. These figures show that there is mixed evidence of the sign of the risk premium and, besides, the risk premia are strongly timevarying. Hence, the activity of speculators is also timevarying. In Figure 3 we saw that the risk premium for very short maturities was positive; however, in Figure 4 we see that it is not always positive but it is on average. Therefore, in general, the futures price is a downward biased predictor of the expected spot price for short maturities. However, for longer maturities, we see that the risk premium is usually negative, apart from maturities longer than 12 months for the Exponential distribution and longer than 24 months for the Normal distribution, where it is always negative. Then, for maturities longer than 6 months, the futures price is an upward biased predictor of the expected spot price as a whole.

\section{Conclusions}

In this paper, we make mainly two contributions. Firstly, we apply the approach in [11] for pricing natural gas futures, but we assume that the jump size follows an Exponential distribution. We use the data and nonparametric techniques to estimate all the risk-neutral functions of the model as in [11]. Then, considering a higher out-of-sample period, we show that considering a jump-diffusion model provides lower errors than a diffusion model when pricing futures. Furthermore, we also show that the Normal distribution is the best assumption to price short maturity futures. However, the Exponential distribution provides lower errors when pricing long maturity futures.

The second contribution comes through the use of [11] approach and data to price natural gas options and risk premia. We find that, in general, the model with the Exponential distribution overprices option prices with respect to the Normal distribution. We think that, in order to price options more accurately, other state variables should be taken into account.

As far as the risk premia is concerned, we find that this premium is negative more times with the Exponential distribution than with the Normal distribution. These facts should be taken into account when a jump-diffusion is applied to price commodity futures or options. 

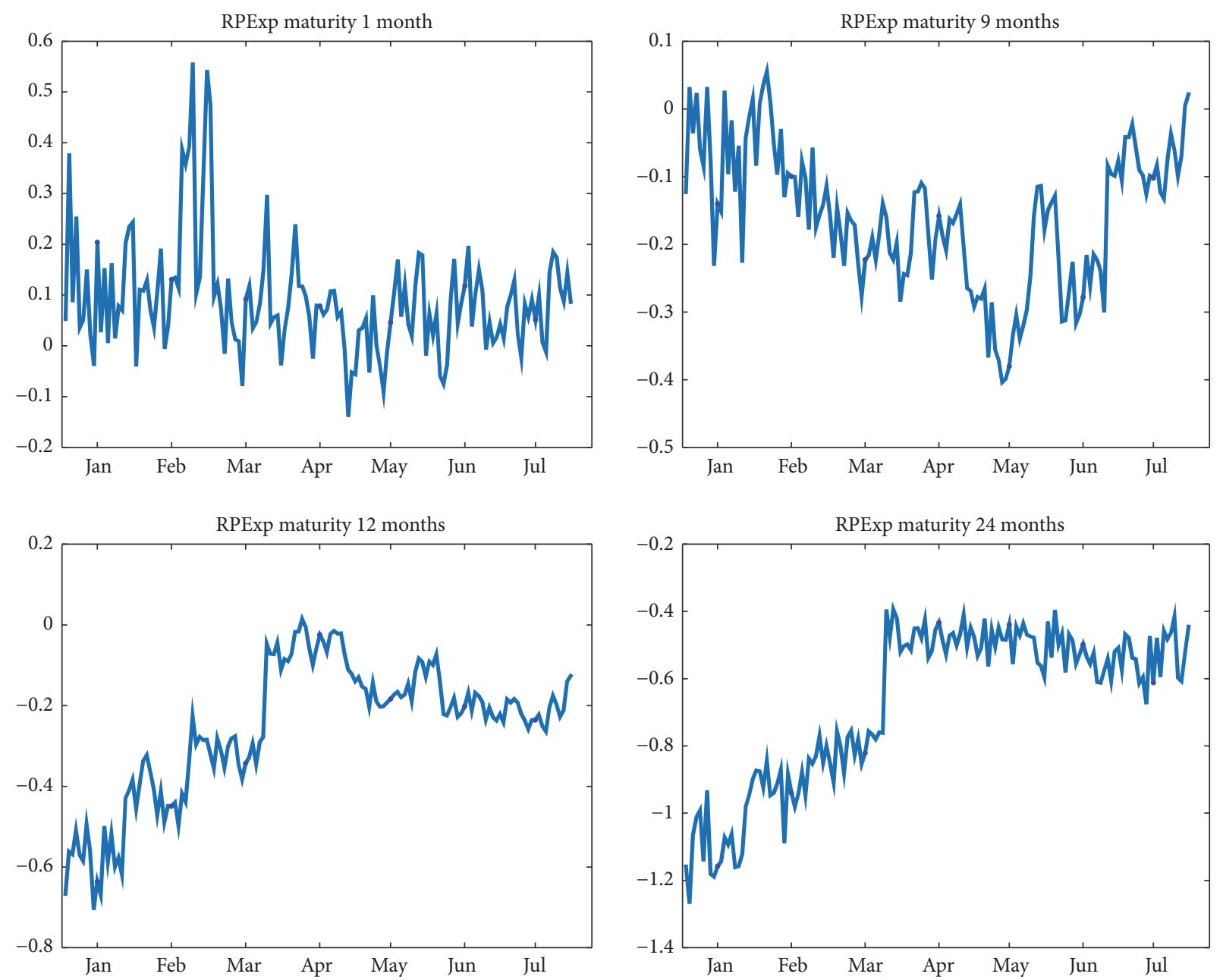

FIGURE 5: The risk premium for the JDMExp model along the out-of-sample, for maturities 1, 9, 12, and 24 months.

Both of these contributions open opportunities for further work. On the one hand, we could consider that the distribution of the jump size under $Q$-measure is not equal to the distribution under $\mathscr{P}$-measure. In this case, we would have to obtain an additional relation to estimate the parameter of the jump size distribution under the risk-neutral measure. On the other hand, it is straightforward to see that a more realistic model should include the effect of seasonality, especially in natural gas markets.

\section{Conflicts of Interest}

The authors declare that they have no conflicts of interest.

\section{Acknowledgments}

L. Gómez-Valle and J. Martínez-Rodríguez were supported in part by the GIR Optimización Dinámica, Finanzas Matemáticas y Utilidad Recursiva of the University of Valladolid, and the Projects VA191U13 of the Consejería de Educación, JCyL and MTM2014-56022-C2-2-P of the Spanish Ministerio de Economía y Competitividad and European FEDER Funds.

\section{References}

[1] S. Deng, "Stochastic models of energy commodity prices and their applications: Mean-reversion with jumps and spikes," Working Paper, University of California Energy Institute, University of California, 2000.

[2] A. Schmitz, Z. Wang, and J.-H. Kimn, "A jump diffusion model for agricultural commodities with bayesian analysis," Journal of Futures Markets, vol. 34, no. 3, pp. 235-260, 2014.

[3] S. Maslyuk, K. Rotaru, and A. Dokumentov, "Price Discontinuities in Energy Spot and Futures Prices," Tech. Rep., Monash University, Department of Economics, Discussion, 2013.

[4] M. Prokopczuk, L. Symeonidis, and C. W. Simen, "Do jumps matter for volatility forecasting? evidence from energy markets," Journal of Futures Markets, vol. 20, pp. 1-15, 2015.

[5] J. E. Hilliard and J. Reis, "Valuation of commodity futures and options under stochastic convenience yields, interest rates, and jump diffusions in the spot," Journal of Financial and Quantitative Analysis, vol. 33, no. 1, pp. 61-86, 1998.

[6] X. Yan, "Valuation of commodity derivatives in a new multifactor model," Review of Derivatives Research, vol. 5, no. 3, pp. 251-271, 2002.

[7] J. E. Hilliard and J. Hilliard, "Estimating early exercise premiums on gold and copper options using a multifactor model and 
density matched lattices," Financial Review, vol. 50, no. 1, pp. 27-56, 2015.

[8] I. Kyriakou, N. K. Nomikos, N. C. Papapostolou, and P. K. Pouliasis, "Affine-Structure Models and the Pricing of Energy Commodity Derivatives," European Financial Management, vol. 22, no. 5, pp. 853-881, 2016.

[9] R. Gibson and E. S. Schwartz, "Stochastic convenience yield and the pricing of oil contingent claims," The Journal of Finance, vol. 45, no. 3, pp. 959-973, 1990.

[10] E. S. Schwartz, "The stochastic behavior of commodity prices: Implications for valuation and hedging," Journal of Finance, vol. 52, no. 3, pp. 923-973, 1997.

[11] L. Gómez-Valle, Z. Habibilashkary, and J. Martínez-Rodríguez, "A new technique to estimate the risk-neutral processes jumpdiffusion commodity futures models," Journal of Computational and Applied Mathematics, vol. 309, pp. 435-441, 2017.

[12] J. Back, M. Prokopczuk, and M. Rudolf, "Seasonality and the valuation of commodity options," Journal of Banking and Finance, vol. 37, no. 2, pp. 273-290, 2013.

[13] A. Cartea and M. G. Figueroa, "Pricing in electricity markets: A mean reverting jump diffusion model with seasonality," Applied Mathematical Finance, vol. 12, pp. 313-335, 2015.

[14] J. C. Arismendi, J. Back, M. Prokopczuk, R. Paschke, and M. Rudolf, "Seasonal Stochastic Volatility: Implications for the pricing of commodity options," Journal of Banking and Finance, vol. 66, pp. 53-65, 2016.

[15] L. Li, R. Mendoza-Arriaga, Z. Mo, and D. Mitchell, "Modelling electricity prices: a time change approach," Quantitative Finance, vol. 16, no. 7, pp. 1089-1109, 2016.

[16] M. Szymanowska, F. De Roon, T. Nijman, and R. Van Den Goorbergh, "An Anatomy of Commodity Futures Risk Premia," Journal of Finance, vol. 69, no. 1, pp. 453-483, 2014.

[17] S. Wei and Z. Zhu, "Commodity convenience yield and risk premium determination: The case of the U.S. natural gas market," Energy Economics, vol. 28, pp. 523-534, 2006.

[18] C. Protter, Stochastic Integration and Differential Equations, Springer Verlag, New York, USA, 2004.

[19] D. Applebaum, Lévy Processes and Stochastic Calculus, Cambridge University Press, Cambridge, UK, 2nd edition, 2009.

[20] R. Cont and P. Tankov, Financial Modelling with Jump Processes, Chapman \& Hall, CRC Press, Raton, Florida, USA, 2004.

[21] B. Øksendal and A. Sulem, Applied Stochastic Control of Jump Diffusions, Universitext, Springer-Verlag, Heidelberg, Germany, 2nd edition, 2007.

[22] S. E. Shreve, Stochastic Calculus for Finance II: Continuous Time Models, Springer Finance, New York, USA, 2004.

[23] S. K. Nawalkha, N. Beliaeva, and G. Soto, Dynamic Term Structure Modeling: The Fixed Income Valuation Course, John Wiley \& Sons, 2007.

[24] S. F. Chung and H. Y. Wong, "Analytical pricing of discrete arithmetic Asian options with mean reversion and jumps," Journal of Banking and Finance, vol. 44, pp. 130-140, 2001.

[25] Y. Xiao, D. B. Colwell, and R. Bhar, "Risk Premium in Electricity Prices: Evidence from the PJM Market," Journal of Futures Markets, vol. 35, no. 8, pp. 776-793, 2015.

[26] L. Gómez-Valle and J. Martínez-Rodríguez, "The role of the risk-neutral jump size distribution in single-factor interest rate models," Abstract and Applied Analysis, vol. 2015, Article ID 805695, 8 pages, 2015.
[27] L. Gómez-Valle and J. Martínez-Rodríguez, "Estimation of riskneutral processes in single-factor jump-diffusion interest rate models," Journal of Computational and Applied Mathematics, vol. 291, pp. 48-57, 2016.

[28] W. Härdle, "Applied nonparametric regression," in Econometric Society Monographs, vol. 19, Cambridge University Press, New York, NY, USA, 1990.

[29] D. Duffie, J. Pan, and K. Singleton, “Transform analysis and asset pricing for affine jump-diffusions," Econometrica, vol. 68, no. 6, pp. 1343-1376, 2000.

[30] N. Beliaeva and S. K. Nawalkha, "Pricing American interest rate options under the jump-extended constant-elasticity-ofvariance short rate models," Journal of Banking and Finance, vol. 36, no. 1, pp. 151-163, 2012.

[31] R. Jarrow, H. Li, and F. Zhao, "Interest rate caps 'simle' too! But can the LIBOR market models capture it?" Journal of Finance, vol. 62, no. 1, pp. 345-382, 2007.

[32] F. M. Bandi and T. H. Nguyen, "On the functional estimation of jump-diffusion models," Journal of Econometrics, vol. 116, no. 1-2, pp. 293-328, 2003.

[33] M. Johannes, "The statistical and economic role of jumps in continuous-time interest rate models," The Journal of Finance, vol. 59, no. 1, pp. 227-259, 2004.

[34] G. Figà-Talamanca and A. Roncoroni, "Nonparametric estimation of energy and commodity price process," in Handbook of Multi-Commodity Markets and Products. Structuring, Trading and Risk Management, A. Roncoroni, G. Fusai, and M. Cummins, Eds., John Wiley \& Sons Ltd, Chichester, UK, 2015.

[35] F. M. Bandi and R. Renò, "Time-varying leverage effects," Journal of Econometrics, vol. 169, no. 1, pp. 94-113, 2012.

[36] J. Boudoukh, C. Downing, M. Richardson, and R. Stanton, "A multifactor, nonlinear, continuous-time model of interest rate volatility," in Volatility and time series econometrics: essays in honor of Robert F. Engle, T. Bollerslev, J. Russell, and M. Watson, Eds., Oxford University Press, New York, USA, 2010.

[37] L. Gómez-Valle and J. Martínez-Rodríguez, "Advances in pricing commodity futures: multifactor models," Mathematical and Computer Modelling, vol. 57, no. 7-8, pp. 1722-1731, 2013.

[38] M. Fakharany, R. Company, and L. Jòdar, "Positive finite difference schemes for a partial integro-differential option pricing model," Applied Mathematics and Computation, vol. 249, pp. 320-332, 2014.

[39] M. C. Calvo-Garrido, M. Ehrhardt, and C. Vázquez, "Pricing swing options in electricity markets with two stochastic factors using a partial differential equation approach," Journal of Computational Finance, vol. 20, no. 3, pp. 81-107, 2017.

[40] P. Wilmott, Paul Wilmott Introduces Quantitative Finance, John Wiley \& Sons, West Sussex, UK, 2001.

[41] R. Weron, "Market price of risk implied by Asian-style electricity options and futures," Energy Economics, vol. 30, pp. 1098$1115,2015$.

[42] A. E. D. Veraart and L. A. M. Veraart, "Risk premia in energy markets," Tech. Rep., Aarhus University, 2013, CREATES Research Paper 2013-12, Department of Economics and Business Economics.

[43] A. Cartea and T. Williams, "UK gas markets: The market price of risk and applications to multiple interruptible supply contracts," Energy Economics, vol. 30, no. 3, pp. 829-846, 2008. 


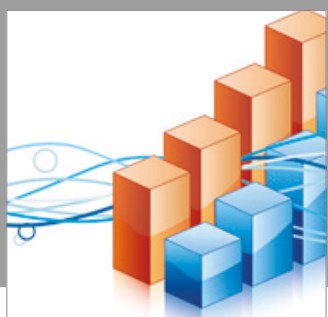

Advances in

Operations Research

vatersals

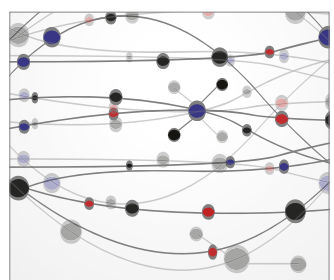

\section{The Scientific} World Journal
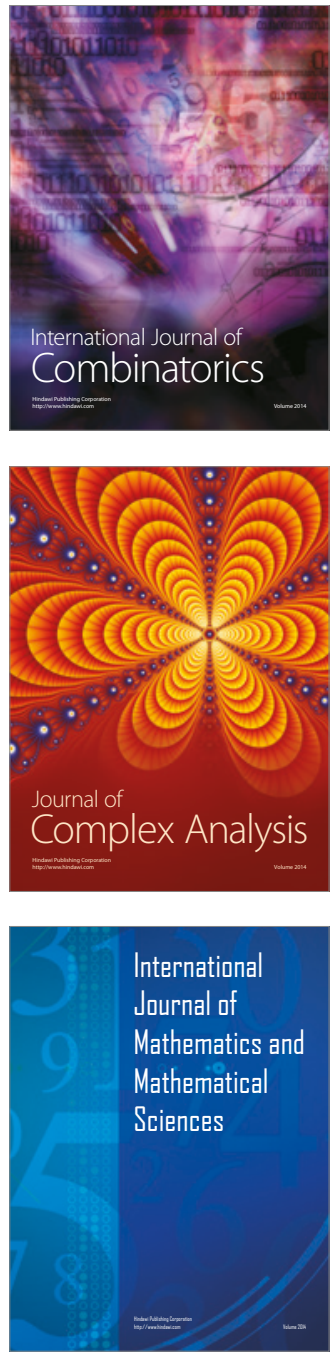
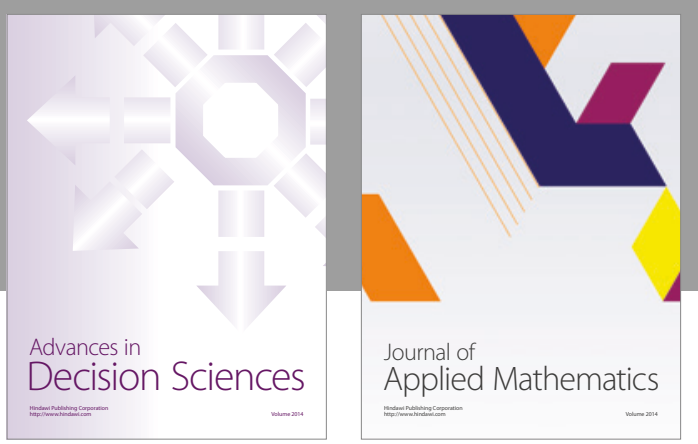

Algebra

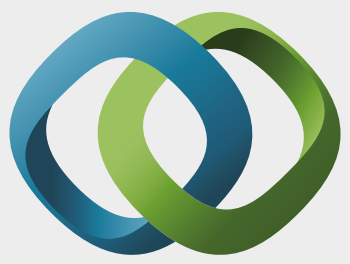

\section{Hindawi}

Submit your manuscripts at

https://www.hindawi.com
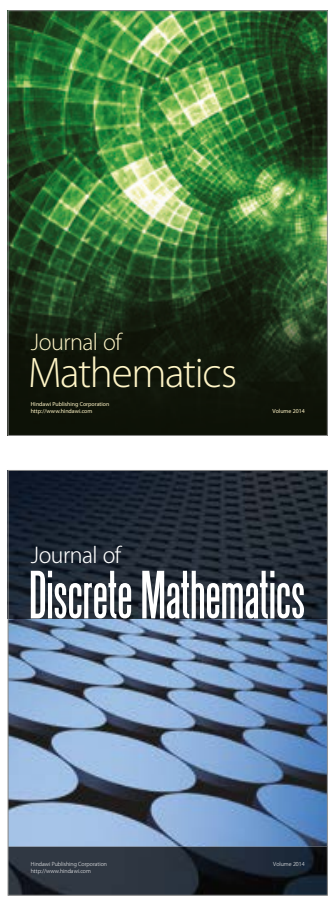

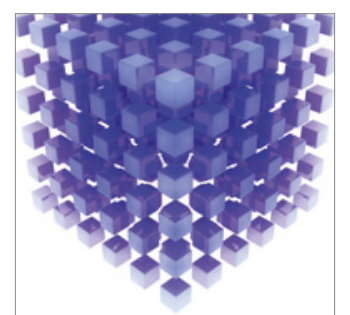

Mathematical Problems in Engineering
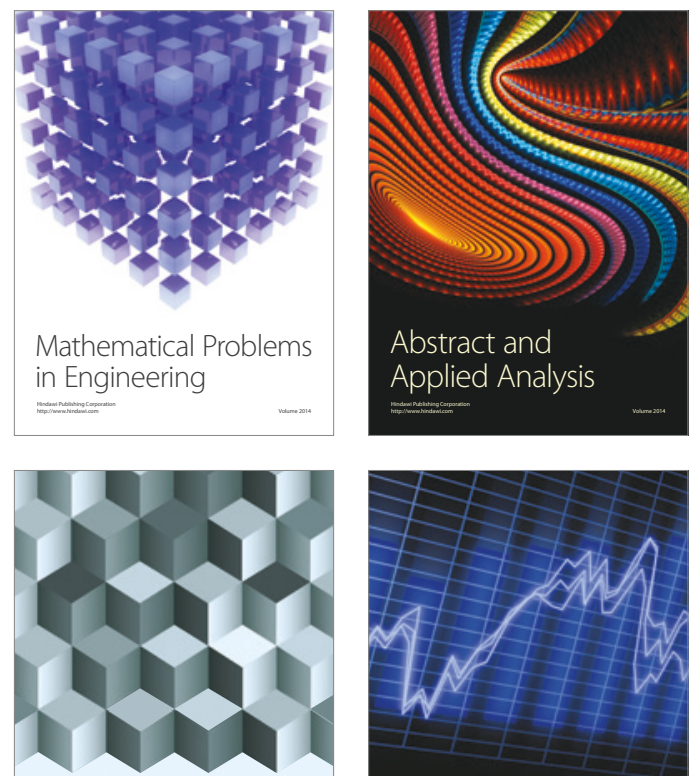

Journal of

Function Spaces

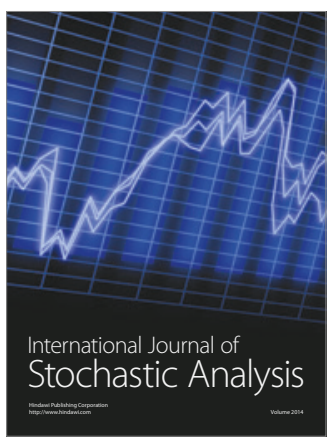

Probability and Statistics
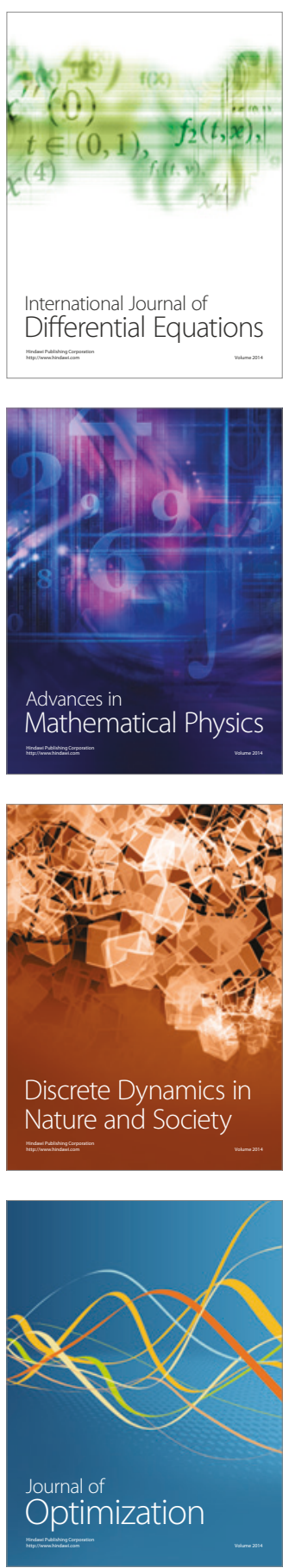